\title{
Stable incidence of advanced breast cancer argues against screening effectiveness
}

\author{
Philippe Autier professor and research director, Cécile Pizot statistician, Mathieu Boniol professor \\ and senior statistician
}

University of Strathclyde Institute of Global Public Health at iPRI, International Prevention Research Institute (iPRI), Espace Européen d'Ecully, 69130 Ecully Ouest Lyon, France

Swedish trials on mammography screening of women aged 40-74 years indicated that two to four rounds of screening could significantly reduce the risk of being diagnosed with and dying from advanced breast cancer. ${ }^{1}$ Because stage at diagnosis is independent of treatment efficacy, the trials concluded that the introduction of screening in general populations would be reflected by a reduced incidence of advanced breast cancer and mortality from breast cancer.

However, De Glas and colleagues show that mammography screening of Dutch women aged 70-74 years has only a modest influence on the incidence of advanced breast cancer. ${ }^{2}$ US, Australian, and European studies in communities with a long history of screening and a high participation rate, where women have attended more screening rounds than in the Swedish trials, report similar findings for advanced breast cancer, including very large or metastatic cancer. ${ }^{3-5}$ The quasi stable incidence of advanced breast cancer over time is not compatible with screening having a major role in the reductions in breast cancer mortality seen in most high income countries.

This situation contrasts sharply with that seen for colorectal and cervical cancer screening. Marked declines in the incidence of advanced forms of both these cancers, as well as mortality, are seen where screening is widespread, which agrees with results of randomised trials. ${ }^{67}$ For breast cancer, the discrepancies between trial results and epidemiological data can probably be explained by the Swedish trials overestimating reductions in the risk of advanced cancer and of cancer death associated with mammography screening.

Competing interests: None declared.

Full response at: www.bmj.com/content/349/bmj.g5410/rr/764626.

1 Smith RA, Duffy SW, Gabe R, Tabar L, Yen AM, Chen TH. The randomized trials of breast cancer screening: what have we learned? Radiol Clin North Am 2004;42:793-806.

2 De Glas NA, de Craen AJ, Bastiaannet E, Op't Land EG, Kiderlen M, van de Water W, et al. Effect of implementation of the mass breast cancer screening programme in older women in the Netherlands: population based study. BMJ 2014;349:g5410. (14 September.)

3 Autier P, Boniol M, Middleton R, Doré J-F, Héry C, Zheng T, et al. Advanced breast cance incidence following population-based mammographic screening. Ann Oncol 2011;22:1726-35.

4 Bleyer A, Welch HG. Effect of three decades of screening mammography on breast-cance incidence. N Engl J Med 2012;367:1998-2005.

5 Lousdal ML, Kristiansen IS, Moller B, Støvrin H. Trends in breast cancer stage distribution before, during and after introduction of a screening programme in Norway. Eur J Public Health 2014; published online 4 March.

6 Sigurdsson K, Sigvaldason H. Effectiveness of cervical cancer screening in Iceland, 1964-2002: a study on trends in incidence and mortality and the effect of risk factors. Acta Obstet Gynecol Scand 2006:85:343-9.

Edwards BK, Ward E, Kohler BA, Eheman C, Zauber AG, Anderson RN, et al. Annual report to the nation on the status of cancer, 1975-2006, featuring colorectal cancer trends and impact of interventions (risk factors, screening, and treatment) to reduce future rates. Cancer 2010;116:544-73.

Cite this as: BMJ 2014;349:96358

(๑) BMJ Publishing Group Ltd 2014 